\title{
A nationwide study on the prevalence of functional gastrointestinal disorders in school-children
}

\author{
Miguel Saps ${ }^{1}$, Jairo Enrique Moreno-Gomez ${ }^{2}$, Carmen Ramírez-Hernández ${ }^{3}$, John M. Rosen ${ }^{4 *}$ and \\ Carlos A. Velasco-Benitez ${ }^{5}$ \\ ${ }^{1}$ Department of Pediatric Gastroenterology, Hepatology and Nutrition, Nationwide Children's Hospital, Columbus, OH, USA; ${ }^{2}$ Clinica Pediatrica \\ Colsanitas, Bogotá, Colombia; ${ }^{3}$ Hospital Regional María Inmaculada, Florencia, Colombia; ${ }^{4}$ Division of Pediatric Gastroenterology, Hepatology, and \\ Nutrition, Children's Mercy Hospital, Kansas City, MO, USA; ${ }^{5}$ Departamento de Pediatría, Universidad del Valle, Cali, Colombia
}

\begin{abstract}
Introduction: Functional gastrointestinal disorders (FGIDs) are highly prevalent worldwide and are thought to result from the interplay of multiple factors that can vary from region to region. Nationwide studies can help understand the regional epidemiology and the pathogenesis of FGIDs. The objectives of this study were to determine the prevalence of FGIDs in school-children of Colombia and assess associated factors. Methods: A cross-sectional study was carried out at 12 private and public schools in 10 cities distributed through the four main geographic regions of Colombia. School-children completed a validated questionnaire to assess functional gastrointestinal disorders according to Rome III criteria. Demographic information and past medical and family history were obtained from the parents. Results: 4394/5062 (86.8\%) children participated in the study, with ages ranging from 8-18 years (mean $=11.9, S D=2.3$ ). $23.7 \%$ of children had at least one FGID. Disorders of defecation were the most common category FGID (11.7\%) followed by abdominal pain-related functional gastrointestinal disorders (10.4\%). Children have increased odds of FGIDs if they have separated parents (OR 1.22, $p=0.007$ ), attend private school (OR 1.54, $p<0.001$ ), or have nausea (OR 3.16, $p<0.001$ ). Conclusions: This large epidemiological study of pediatric FGIDs is the first to evaluate a broad cross-section of children throughout a nation in the Americas. High prevalence of FGIDs and identified associations with their likelihood are relevant when providing medical care and when planning public health efforts.
\end{abstract}

Key words: Functional gastrointestinal disorder. Abdominal pain. Constipation. Pediatric. Latin America.

\section{Prevalencia de desórdenes gastrointestinales funcionales en niños. Un estudio a nivel nacional}

\section{Resumen}

Introducción: Los desórdenes gastrointestinales funcionales (DGF) son altamente prevalentes a nivel mundial. Se postula que estos desórdenes resultan del interjuego de múltiples factores que pueden variar regionalmente. Estudios a nivel nacional pueden ayudar a comprender la epidemiología regional y la patogénesis de los DGFs. Los objetivos del estudio fueron determinar la prevalencia de DGFs en escolares en Colombia y establecer los factores asociados. Métodos. Estudio de corte transversal realizado en 12 escuelas privadas y públicas en 10 ciudades de las 4 regiones principales de Colombia.

\section{Correspondence:}

*John M. Rosen

Email: jmrosen@cmh.edu

2444-3409/@ 2018. Hospital Infantil de México Federico Gómez, published by Permanyer México SA de CV, all rights reserved.
Received: 21-02-2017

Accepted: 11-05-2017

DOI: 10.24875/BMHIME.M17000012
Available online: 25-06-2018 Bol Med Hosp Infant Mex. 2017;74:405-410 www.bmhim.com 
Niños de edad escolar completaron un cuestionario validado para diagnosticar DGFs de acuerdo con los criterios de Roma III. Información demográfica e historia personal y familiar fue obtenida de los padres. Resultados: 4394/5062 (86.8\%) niños participaron en el estudio, rango de edad 8-18 años (promedio = 11.9, Desviación Estándar $(D E)=2.3$ ). 23.7\% de los niños tuvieron al menos un DGF. Los desórdenes de la defecación fueron los más frecuentes (11.7\%), seguidos por desórdenes funcionales de dolor (10.4\%). Niños cuyos padres estaban separados (Razón de momios (RM) 1.22, $p=0.007$ ), cursaban en escuela privada ( $R M 1.54, p<0.001$ ) o reportaban náuseas (RM 3.16, $p<0.001$ ) tuvieron mayor riesgo de DGFs. Conclusiones: Este estudio de DGFs es el primero en evaluar un grupo numeroso de niños en diferentes regiones de un país americano. La alta prevalencia de DGFs y la identificación de asociaciones que aumentan el riesgo de desarrollar estos desórdenes son hallazgos relevantes para proveer cuidados médicos y planear estrategias de salud pública.

Palabras clave: Desórdenes gastrointestinales funcionales. Dolor abdominal. Estreñimiento. Pediatría. Latinoamérica.

\section{Introduction}

Thirty-eight percent of school-children report abdominal pain weekly ${ }^{1}$, but only $2-4 \%$ of children who report abdominal pain seek medical consultation ${ }^{1,2}$. Despite this, abdominal pain is the most common cause of consultation with the pediatric gastroenterologist. Out of all children (> 4 years) who consulted pediatric gastroenterology in a tertiary care center in the US, $52 \%$ consulted for an abdominal pain associated-functional gastrointestinal disorder (AP-FGID) ${ }^{3}$. The cost of care of children with APFGIDs is substantial. In the Netherlands, the costs of care for a child with AP-FGIDs exceeds €25004. The overall cost of care for AP-FGIDs in the US grew by $300 \%$ in a 12-year period ${ }^{5}$, and evaluation of a single child for an AP-FGIDs in the US is estimated $>\$ 6000^{6}$. The cost of a single consultation for abdominal pain in Uruguay accounted for $3.8 \%$ of the per capita health care spending of one year?. Although the economic impact of AP-FGIDs has not been studied in most countries, it is likely to be a global economic problem based on the high worldwide prevalence of FGIDs.

The magnitude of the problem calls for preventative measures and plans of care adapted to local needs. However, to establish what the local needs are, it is imperative first to obtain reliable data on the local epidemiology. Due to the low ratio of consultation for abdominal pain, studies performed at the doctor's office are prone to selection bias. Thus, only community studies provide the information needed. Conducting epidemiological studies in private and public schools allow obtaining data from children with different socio-economic statuses. There have been several school studies investigating the prevalence of FGIDs. However, none of them were conducted in private and public schools in multiple cities throughout different regions of one country.

In addition to establishing the regional epidemiology, nationwide studies provide a unique opportunity to achieve a better understanding of the pathogenesis of
FGIDs that is currently elusive. This information is key to establish prevention strategies and effective treatments. The most accepted model to explain FGIDs propose that these disorders result from the interaction of the child's genetic background, early life experiences, intestinal microbiota, as well as psychological and social influences. As these factors vary by region, establishing comparisons among regions could help advance the knowledge of the pathogenesis of FGIDs.

We conducted a large school-based study of FGIDs in multiple cities in Colombia using standardized methods, validated questionnaires adapted to the terms used by children, and the Rome III diagnostic criteria. This study aims to evaluate the prevalence of pediatric FGIDs throughout Colombia and determine if regional differences exist, as well as to identify associated factors.

\section{Methods}

The present study is the largest study conducted by the Functional International Digestive Epidemiological Research Survey (FINDERS) group and the broadest national study in the Western Hemisphere on FGIDs in children. This cross-sectional study was carried out at 12 schools in 10 cities of Colombia. Colombia is the second most populated country in South-America, with a population of approximately 50 million $^{8}$ inhabitants. Most of the population is concentrated along the Caribbean coast and the Andean regions. In Colombia, 85\% of primary care education students and $60 \%$ of the secondary-school level students attend to public schools ${ }^{9}$. To enhance racial, ethnic, and socioeconomic diversity and maximize the external validity of the data, we selected public and private schools as study sites. The study was purposefully designed to enroll a higher proportion of children from public over private schools to resemble the education system of the country. To better represent the population distribution of Colombia, we selected more cities with high population density. The 
cities of the study are distributed through the four main regions of Colombia, the Caribbean region (adjacent to the Caribbean Sea), Andean region (by the mountains), the Amazon region (tropical rainforest), and the Pacific region (neighboring the Pacific Ocean). Together, these four regions hold $97.3 \%$ of the population in Colombia.

To ensure consistency and to allow comparison within multi-national cross-cultural studies, the study was conducted systematically following the same methods used in previous studies by the international consortium FINDERS ${ }^{1,10-12}$. The methods used by FINDERS were based on two school-studies performed previously and a prior small study by FINDERS in Colombia. The first study was piloted in a single school in Pittsburgh ${ }^{13}$ followed by a larger study in Chicago to streamline methods ${ }^{2}$. Planning of the current study in Colombia started by translating the English version of the QPGS-III questionnaire into Spanish and local language according to established standards. The self-report child version of the QPGS-III questionnaire (a validated instrument created to assess the full spectrum of FGIDs according to the Rome III criteria) was first translated into Spanish by a bilingual pediatric gastroenterologist and two bilingual medical students, followed by the reverse translation of the QPGS-III by another member of the research team. The resulting English version was then compared with the original English version of the QPGS-III by a native English speaker who was not part of the research team to ascertain fidelity. The finalized Spanish version of the QPGS-III was then presented to two focus groups of children in two different cities in Colombia (Cali and Pasto) to ensure that the terms were adequately understood. Once the Spanish version of the QPGS-III was tested in the focus groups, the methods and the Spanish version of the questionnaire was again tested in the first study by FINDERS in Pasto, Colombia ${ }^{1}$. The data obtained from this study using the Spanish version of the QPGS III were analyzed statistically for internal consistency using Cronbach's alpha analysis ${ }^{14}$. The study showed high internal consistency. In short, the methods used in the current study were the following: parents of children 8-18 years of age received a package with information on the study at home, a questionnaire on their child's past medical history and a consent form. Children who assented (and whose parents consented) to participate in the study underwent an informative session in class explaining the study and questionnaires. The participants completed the data forms in class with a member of the research team available for questions. The data were entered into an electronic database. In order to ensure the accuracy of data transfer, $10 \%$ of the questionnaires were reviewed and compared with the paper forms collected at the school level.
The study was approved by the principal of each of the schools and by the Institutional Review Board and Human Subjects Committee of Universidad del Valle of Cali, Colombia.

Statistical analysis included the calculation of odds ratios, $95 \%$ confidence intervals, and $p$ values to describe the associations of interest (Stata 10 software, College Station, Texas). Fisher's exact test was used when appropriate. Two-sided $p$ values of $<0.05$ were considered statistically significant.

\section{Results}

A total of 5062 families were sent the information package and invited to participate in the study. 4394/5062 (86.8\%) dyads (children/caretaker) assented/consented to participate. Participants ranged from 8 to 18 years of age $($ mean $=11.9, S D=2.3)$. There were 2279 boys (51.9\%) and 2115 (48.1\%) girls; 2702 (61.5\%) were children (8 to 12 years) and $1692(38.5 \%)$ adolescents (13 to 18 years). Most children who participated in the study were from public schools 3546 (80.7\%), and $848(19.3 \%)$ were from private schools.

\section{FGID prevalence}

Regarding FGID prevalence, $23.7 \%$ of children in the total sample had at least one FGID (Table 1). The range of FGID per region varied between $19.8 \%$ (Pacific region) to $26.5 \%$ (Amazonia region). There was a significant difference in FGID prevalence between regions $(p=$ 0.001 ). Additional analysis of regional FGID prevalence identified differences between Andean and Pacific regions $(p<0.001)$ and Amazonia and Pacific regions $(p$ $=0.007$ ). Disorders of defecation (functional constipation and non-retentive fecal incontinence) were the most common category of FGIDs (11.7\%), followed by APFGIDs (10.4\%) and vomiting/aerophagia (1.6\%). Functional constipation accounted for nearly all disorders of defecation ( $n=509 / 512,99.4 \%)$, and IBS was the most common AP-FGIDs ( $n=222 / 457,48.6 \%$ ).

\section{Demographics and family}

FGIDs were significantly less common in adolescents than children (21.5\% vs. $25.1 \%$, OR 0.82) (Table 2). Males had significantly fewer FGIDs than females $(21.9 \%$ vs. $25.6 \%$, OR 0.81 ). Concerning the marital status of the parents, 2189 children had married parents, and there was a higher prevalence of FGIDs among children whose parents were separated/divorced $(25.3 \%$ 
Table 1. Prevalence of functional gastrointestinal disorders by region

\begin{tabular}{|l|c|c|c|c|c|}
\hline & Andean & Atlantic & Pacific & Amazonia & \multicolumn{2}{c|}{ Colombia } \\
\hline Total & 1544 & 1373 & 1085 & 392 & 4394 \\
\hline No FGIDs & $1141(73.9 \%)$ & $1055(76.8 \%)$ & $870(80.2 \%)$ & $288(73.5 \%)$ & $3354(76.3 \%)$ \\
\hline FGIDs & $403(26.1 \%)$ & $318(23.2 \%)$ & $215(19.8 \%)$ & $104(26.5 \%)$ & $1040(23.7 \%)$ \\
\hline Vomiting and aerophagia & & & & $71(1.6 \%)$ \\
$\quad \begin{array}{l}\text { Aerophagia } \\
\text { Cyclic vomiting syndrome }\end{array}$ & $7(0.5 \%)$ & $19(1.4 \%)$ & $11(1.0 \%)$ & 0 & $37(0.8 \%)$ \\
\hline Adolescent Rumination Syndrome & $5(0.3 \%)$ & $5(0.4 \%)$ & $5(0.5 \%)$ & $2(0.5 \%)$ & $17(0.4 \%)$ \\
\hline Abdominal pain predominant-FGIDs & $4(0.3 \%)$ & $9(0.7 \%)$ & $3(0.3 \%)$ & $1(0.3 \%)$ & $17(0.4 \%)$ \\
\hline $\begin{array}{l}\text { Functional dyspepsia } \\
\text { IBS }\end{array}$ & $13(0.8 \%)$ & $11(0.8 \%)$ & $16(1.5 \%)$ & $6(1.5 \%)$ & $457(10.4 \%)$ \\
\hline $\begin{array}{l}\text { Abdominal migraine } \\
\text { Functional abdominal pain }\end{array}$ & $87(5.6 \%)$ & $68(5.0 \%)$ & $49(4.5 \%)$ & $18(4.6 \%)$ & $222(5 \%)$ \\
\hline Functional abdominal pain syndrome & $36(2.3 \%)$ & $12(0.9 \%)$ & $24(2.1 \%)$ & $4(1.0 \%)$ & $76(1.7 \%)$ \\
\hline $\begin{array}{l}\text { Constipation and incontinence } \\
\text { Functional constipation }\end{array}$ & $22(2.0 \%)$ & $18(1.3 \%)$ & $19(1.8 \%)$ & $8(2.0 \%)$ & $76(1.7 \%)$ \\
\hline Non-retentive fecal incontinence & $5(0.4 \%)$ & $9(0.8 \%)$ & $1(0.3 \%)$ & $37(0.8 \%)$ \\
\hline
\end{tabular}

FGID, Functional gastrointestinal disorder; IBS, irritable bowel syndrome

Table 2. Relationship between the presence of FGIDs and sociodemographic and familial variables in children in Colombia

\begin{tabular}{|c|c|c|c|c|c|}
\hline Variable & Total (n) & FGID (n) & OR & $95 \%$ CI & $p$-value \\
\hline \multicolumn{6}{|l|}{ Sociodemographics } \\
\hline $\begin{array}{l}\text { Age (years) } \\
\text { Children (8-12) } \\
\text { Adolescent (13-18) }\end{array}$ & $\begin{array}{l}2702 \\
1692\end{array}$ & $\begin{array}{l}677 \\
363\end{array}$ & $\begin{array}{c}1 \\
0.82\end{array}$ & $0.71-0.94$ & $<0.01$ \\
\hline $\begin{array}{l}\text { Gender } \\
\text { Female } \\
\text { Male }\end{array}$ & $\begin{array}{l}2115 \\
2279\end{array}$ & $\begin{array}{l}542 \\
498\end{array}$ & $\begin{array}{c}1 \\
0.81\end{array}$ & $0.71-0.93$ & $<0.01$ \\
\hline $\begin{array}{l}\text { School type } \\
\text { Public } \\
\text { Private }\end{array}$ & $\begin{array}{c}3546 \\
848\end{array}$ & $\begin{array}{l}782 \\
258\end{array}$ & $\begin{array}{c}1 \\
1.54\end{array}$ & $1.30-1.83$ & $<0.01$ \\
\hline \multicolumn{6}{|l|}{ Familial } \\
\hline $\begin{array}{l}\text { Divorced or separated parents } \\
\text { No } \\
\text { Yes }\end{array}$ & $\begin{array}{l}2189 \\
1849\end{array}$ & $\begin{array}{l}475 \\
468\end{array}$ & $\begin{array}{c}1 \\
1.22\end{array}$ & $1.05-1.41$ & $<0.01$ \\
\hline $\begin{array}{l}\text { History of FGIDs } \\
\text { Yes } \\
\text { No }\end{array}$ & $\begin{array}{c}261 \\
3939\end{array}$ & $\begin{array}{c}71 \\
916\end{array}$ & $\begin{array}{c}1 \\
1.23\end{array}$ & $0.91-1.64$ & 0.14 \\
\hline $\begin{array}{l}\text { Siblings } \\
\text { With siblings } \\
\text { Without siblings }\end{array}$ & $\begin{array}{c}3692 \\
501\end{array}$ & $\begin{array}{l}864 \\
125\end{array}$ & $\begin{array}{c}1 \\
1.08\end{array}$ & $0.86-1.35$ & 0.44 \\
\hline
\end{tabular}

FGID, Functional gastrointestinal disorder; OR, Odds ratio; $\mathrm{Cl}$, Confidence interval

vs. $21.7 \%$, OR 1.22). Children from private schools had significantly more FGIDs than children from public schools ( $30.4 \%$ vs. $22.1 \%$, OR 1.54$)$. There was a greater frequency of FGIDs among children with parents who had FGIDs, but the difference was not significant (37.4\% vs. $23.3 \%$, OR 1.23 ). There was no difference in prevalence of FGIDs between children with and without siblings ( $23.4 \%$ vs. $25.0 \%$, OR 1.08$)$. 


\section{Association with nausea}

Nausea was reported in $10.5 \%$ of all children and was significantly more common among children with FGIDs (OR 3.63; 95\% Cl 2.96-4.44; $p<0.001$ ). There was an association of nausea with most FGIDs: IBS (OR 5.10; $95 \% \mathrm{Cl} 3.74-6.92 ; p<0.001$ ), functional abdominal pain (OR 4.71; 95\% Cl 2.18-9.71; $p<0.001$ ), abdominal migraine (OR 4.62; 95\% $\mathrm{Cl} 2.73-7.66 ; p<0.001$ ), functional dyspepsia (OR $3.80 ; 95 \% \mathrm{Cl} 1.86-7.40 ; p<0.001$ ), and functional constipation (OR 1.42; $95 \% \mathrm{Cl} 1.06-1.87$; $p=0.011)$. There was no significant association between nausea and aerophagia, rumination, cyclic vomiting syndrome, or non-retentive fecal incontinence.

\section{Discussion}

The present study is the largest epidemiological study conducted in the Western Hemisphere aimed at describing FGIDs in children using the Rome III criteria. The study included 4394 children from 12 public and private schools in 10 geographically dispersed cities in Colombia, providing a broad-based survey throughout a Latin American nation. The nationwide distribution of our sample and the high acceptance rate to participate in the study $(86.8 \%)$ indicates the external validity of our data. We found that almost one in four children (23.7\%) had an FGID according to the Rome III criteria. The prevalence of FGIDs found in this study was similar to that found in Quito $(22.8 \%)^{12}$, the capital of Ecuador, which borders Colombia to the South. Similar to the results of this study (11.6\%), functional constipation was the most common FGID in Ecuador (11.8\%).

We found that $10.4 \%$ of children in Colombia had APFGIDs, which again is within close range to the prevalence of AP-FGIDs found in Ecuador (9.4\%) using the same methods ${ }^{12}$. A review of AP-FGIDs in children found that worldwide pooled prevalence of AP-FGIDs was higher than in our sample $13.5 \%(95 \% \mathrm{Cl} 11.8$ $15.3)^{15}$. The study identified IBS as the most common AP-FGID, but at higher rates $(8.8 \%, 95 \% \mathrm{Cl} 6.2-11.9)$ than in our study $(5.1 \%)$. The study found a high range of AP-FGID prevalence across countries ranging from $1.6 \%$ to $41.2 \%$. Prevalence of adult IBS is estimated to be $21-26 \%$ in Peru $^{16}$ and $19.9 \%$ in Colombia, which are higher than the present results in children. The reasons for the differences in the prevalence of AP-FGIDs between children and adults and among geographic regions remains unknown and should be studied with large international comparative studies using standardized methodology and subjects of different age groups.
FGIDs were more common in children from private than public schools and in children whose parents were separated. Another Latin-American study also found that children from divorced/separated families had a higher prevalence of FGIDs ${ }^{11}$ than children from intact families. Although the design of this study does not allow determination of causality, the results are in line with the biopsychosocial model that proposes psychological and social factors play a role in the pathogenesis of FGIDs. According to the biopsychosocial model, AP-FGID symptoms result from the interaction of gastrointestinal and central nervous system factors ${ }^{17}$. Stress has pathophysiological effects in the gastrointestinal tract. $\mathrm{Hi}-$ gher stress levels can trigger or exacerbate abdominal pain through visceral hypersensitivity and changes in motility. Children with depressive or anxious symptoms are more likely to suffer from AP-FGIDs ${ }^{18}$ and studies in school-children found an association between anxiety and depression with abdominal pain ${ }^{19}$. Divorce is a major stressor ${ }^{20}$, and parental separation and divorce are associated with higher rates of depression ${ }^{21}$. Studies comparing early adolescents from divorced and intact families found that adolescents from divorced families had a higher rate of anxiety and more depressed mood 22 . A higher prevalence of FGIDs in children from private schools was also found in other studies conducted in Latin-American countries such as El Salvador ${ }^{11}$ and Ecuador ${ }^{12}$. A study that interviewed more than 500 adolescents in Colombia found higher levels of anxiety among children of public schools ${ }^{23}$. However, the study was performed in a single town near Bogota, and it is also known that the interrelation between the psychological factors involved in the pathogenesis of FGIDs is complex ${ }^{24}$. Moreover, other non-psychological factors could explain these findings. Future studies by FINDERS will specifically investigate these issues.

Despite previous studies in the United States showing that children of parents with IBS reported more GI symptoms ${ }^{25,26}$, we did not find an association between FGIDs and family history. A family history of FGIDs also did not associate with a higher prevalence of FGIDs in Salvadoran children ${ }^{11}$. The reason for this difference is unclear. Cultural differences in the way an FGID is conceptualized and differences in parenting and coping styles between the US and Latin-American societies may explain these differences.

We did not find gender predominance in FGIDs. These results are similar to those of pediatric studies in Mexico $^{27}$, Ecuador ${ }^{12}$, Panama ${ }^{10}$, and El Salvador ${ }^{11}$. A meta-analysis by Lovell and Ford ${ }^{16}$ found a female predominance in adults with IBS. However, this 
difference was not found when South-American studies were analyzed as a whole.

Limitations of our study include the completion of questionnaires exclusively by children and not by parents. It can be argued that children know their symptoms better than their parents and may be reluctant to share information regarding bowel movements with their parents while being comfort reporting on an anonymous questionnaire. We cannot rule out the possibility that although our study included multiple cities in various regions, the results may not be generalized to all cities in Colombia. Additionally, concurrent medical diagnoses may be present in surveyed children with or without FGIDs and were not assessed in the study.

In conclusion, this study provides relevant information for public health planning, finding a high prevalence of FGIDs in children of Colombia. Children from private schools and from families whose parents have separated are at higher risk of FGIDs, and nausea is associated with increased rates of FGIDs in children.

\section{Ethical disclosures}

Protection of human and animal subjects. The authors declare that no experiments were performed on humans or animals for this study.

Confidentiality of data. The authors declare that they have followed the protocols of their work center on the publication of patient data.

Right to privacy and informed consent. The authors declare that no patient data appear in this article.

\section{Funding}

There was no external source of funding related to this research.

\section{Conflict of interest}

The authors declare no conflicts of interest.

\section{References}

1. Saps M, Nichols-Vinueza DX, Rosen JM, Velasco-Benitez CA. Prevalence of functional gastrointestinal disorders in Colombian school children. J Pediatr. 2014;164:542-5 e1. doi: 10.1016/j.jpeds.2013.10.088.

2. Saps $M$, Seshadri $R$, Sztainberg $M$, Schaffer $G$, Marshall BM, Di Lorenzo C. A prospective school-based study of abdominal pain and other common somatic complaints in children. J Pediatr. 2009;154:322-6. doi: 10.1016/j.jpeds.2008.09.047.

3. Rouster AS, Karpinski AC, Silver D, Monagas J, Hyman PE. Functional gastrointestinal disorders dominate pediatric gastroenterology outpatient practice. J Pediatr Gastroenterol Nutr. 2016;62:847-51. doi: 10.1097/ MPG.0000000000001023.

4. Hoekman DR, Rutten JM, Vlieger AM, Benninga MA, Dijkgraaf MG. Annual costs of care for pediatric irritable bowel syndrome, functional abdominal pain, and functional abdominal pain syndrome. $\mathrm{J}$ Pediatr. 2015;167:1103-8 e2. doi: 10.1016/j.jpeds.2015.07.058.

5. Park R, Mikami S, LeClair J, Bollom A, Lembo C, Sethi S, et al. Inpatient burden of childhood functional GI disorders in the USA: an analysis of national trends in the USA from 1997 to 2009. Neurogastroenterol Motil. 2015;27:684-92. doi: 10.1111/nmo.12542.

6. Dhroove G, Chogle A, Saps M. A million-dollar work-up for abdominal pain: is it worth it? J Pediatr Gastroenterol Nutr. 2010;51:579-83. doi: 0.1097/MPG.0b013e3181de0639.

7. Saps M, Bolioli P, Espana M, Marshall BM, Di Lorenzo C. Cost and consultation patterns of abdominal pain in Uruguayan children. J Pediatr Gastroenterol Nutr. 2008;46:159-63. doi: 10.1097/MPG.0b013e31812e6b1f.

8. http://worldpopulationreview.com/countries/colombia-population. Colombia Population 2016, World Population Review webpage. Accessed February 29, 2016.

9. http://www.bgcenter.com/BGW/ColombianEd.htm. Psychological services for internationally adopted children, Center for Cognitive-Developmental Assessment \& Remediation. Accessed February 29, 2016.

10. Lu PL, Saps M, Chanis RA, Velasco-Benitez CA. The prevalence of functional gastrointestinal disorders in children in Panama: a school-based study. Acta Paediatr. 2016;105:e232-6. doi: 10.1111/apa.13379.

11. Zablah R, Velasco-Benitez CA, Merlos I, Bonilla S, Saps M. Prevalence of functional gastrointestinal disorders in school-aged children in El Salvador.Rev Gastroenterol Mex.2015;80:186-91. doi:10.1016/j.rgmx.2015.03.008.

12. Jativa E, Velasco-Benitez CA, Koppen IJ, Jativa-Cabezas Z, Saps M. Prevalence of functional gastrointestinal disorders in schoolchildren in Ecuador. J Pediatr Gastroenterol Nutr. 2016;63:25-8. doi: 10.1097/ MPG.0000000000001108.

13. Saps M, Sztainberg M, Di Lorenzo C. A prospective community-based study of gastroenterological symptoms in school-age children. J Pediatr Gastroenterol Nutr. 2006;43:477-82. doi: 10.1097/01.mpg.0000235979.41947.f6.

14. Saps M, Velasco C, Nichols-Vinueza D. Validation of the Rome III criteria. High internal consistency of the questionnaire of pediatric gastrointestinal symptoms (Spanish Version). J Pediatr Gastroenterol Nutr. 2012;55:E36-E7.

15. Korterink JJ, Diederen K, Benninga MA, Tabbers MM. Epidemiology of pediatric functional abdominal pain disorders: a meta-analysis. PLoS One. 2015;10:e0126982. doi: 10.1371/journal.pone.0126982.

16. Lovell RM, Ford AC. Effect of gender on prevalence of irritable bowel syndrome in the community: systematic review and meta-analysis. Am J Gastroenterol. 2012;107:991-1000. doi: 10.1038/ajg.2012.131.

17. Tanaka Y, Kanazawa M, Fukudo S, Drossman DA. Biopsychosocial model of irritable bowel syndrome. J Neurogastroenterol Motil. 2011;17:131-9. doi: 10.5056/jnm.2011.17.2.131.

18. Yacob D, Di Lorenzo C, Bridge JA, Rosenstein PF, Onorato M, Bravender $\mathrm{T}$, et al. Prevalence of pain-predominant functional gastrointestinal disorders and somatic symptoms in patients with anxiety or depressive disorders. J Pediatr. 2013;163:767-70. doi: 10.1016/j. jpeds.2013.02.033.

19. Lavigne JV, Saps M, Bryant FB. Models of anxiety, depression, somatization, and coping as predictors of abdominal pain in a community sample of school-age children. J Pediatr Psychol. 2013;39:9-22.

20. Conger R, Chao W. Adolescent Depressed Mood. In: Simon R, editor. Understanding differences between divorced and intact families: Stress interaction and child outcome. Thousand Oaks, CA: Sage; 1996. pp. 157-74.

21. Magklara K, Bellos S, Niakas D, Stylianidis S, Kolaitis G, Mavreas V, et al. Depression in late adolescence: a cross-sectional study in senior high schools in Greece. BMC Psychiatry. 2015;15:199. doi: 10.1186/ s12888-015-0584-9.

22. Garnefski N, Diekstra RF. Adolescents from one parent, stepparent and intact families: emotional problems and suicide attempts. J Adolesc. 1997;20:201-8. doi: 10.1006/jado.1996.0077.

23. Ospina-Ospina FdC, Hinestrosa-Upegui MF, Paredes MC, Guzmán Y, Granados C. [Symptoms of anxiety and depression in adolescents between 10 to 17-year-old attending schools in Chía, Colombia]. Rev Salud Publica (Bogotá). 2011;13:908-20.

24. Lavigne JV, Saps M, Bryant FB. Reexamining the Factor structure of somatization using the children's somatization inventory (CSI-24) in a community sample. J Pediatr Psychol. 2012;37:914-24. doi: 10.1093/ jpepsy/jss060.

25. Levy RL, Whitehead WE, Walker LS, Von Korff M, Feld AD, Garner M, et al. Increased somatic complaints and health-care utilization in children: effects of parent IBS status and parent response to gastrointestinal symptoms. Am J Gastroenterol. 2004;99:2442-51. doi: 10.1111/j.1572-0241.2004.40478.x.

26. van Tilburg MA, Levy RL, Walker LS, Von Korff M, Feld LD, Garner M, et al. Psychosocial mechanisms for the transmission of somatic symptoms from parents to children. World journal of gastroenterology. 2015;21:5532-41. doi: 10.3748/wjg.v21.i18.5532.

27. Dhroove G, Saps M, Garcia-Bueno C, Leyva Jimenez A, Rodriguez-Reynosa LL, Velasco-Benitez CA. Prevalence of functional gastrointestinal disorders in Mexican schoolchildren. Rev Gastroenterol Mex. 2017;82:13-8. doi: 10.1016/j.rgmx.2016.05.003. 